\title{
INTRODUCCIÓN \\ SER AUTORA LATINOAMERICANA. \\ PROCESOS Y ESTRATEGIAS DE AUTOR-REPRESENTACIÓN
}

\author{
POR \\ Fernanda Bustamante Escalona y Aina Pérez Fontdevila \\ Universitat Autònoma de Barcelona Universidad de Alcalá
}

La primera semana de noviembre de 2017, ya dando cierre a la edición de este dossier, en la revista Arcadia se publicó el manifiesto "Colombia tiene escritoras", en el que 43 autoras del país manifestaron su "indignación porque el campo literario colombiano siga invisibilizando a las escritoras", y señalaron como "intolerable que todavía en Colombia se hagan eventos que no incluyan mujeres". Todo ello a raíz de que el Ministerio de Cultura anunciara a los escritores -todos varones- que conformaron la delegación que representaría al país en una actividad que se realizaría en la Bibliothèque de l'Arsenal de París. De hecho, pocos días después, se publicó en la misma revista una columna de Pedro Adrián Zuluaga, que continuó con la polémica, titulada "Tampoco en el cine las mujeres representarán a Colombia en Francia".

Más allá de las respuestas dadas por el Ministerio de Cultura, este debate -un ejemplo más de la sistemática deslegitimación de las mujeres como creadoras culturales e intelectuales a lo largo de la historia- dialoga en gran medida con las preguntas que motivaron este dossier: ${ }^{1}$ para ser reconocida como autora, ¿basta con escribir o con publicar?; ¿cuáles son los procedimientos y protocolos socioculturales por los que una escritora, pensadora o artista entra en escena como autora?; ¿qué agentividad tienen estas figuras autoriales en cuerpos de mujeres latinoamericanas?; ¿qué visados se les exige y cómo reafirman su autogestión en el escenario cultural?; ¿cómo se inscriben -o no- en sus cuerpos las actuales discusiones y narrativas políticas, económicas y culturales?; ¿qué papel desempeñan hoy en día dispositivos como las entrevistas, las fotografías, los blogs/bitácoras personales o medios como Facebook y Twitter en

1 El manifiesto de las escritoras, la columna de Zuluaga y la respuesta del Ministerio de Cultura están disponible en los siguientes enlaces, respectivamente: <http://www.revistaarcadia.com/noticias/ articulo/mujeres-escritoras-colombianas-protestan-discriminacion-politica/66572>, $\quad<$ http://www. revistaarcadia.com/noticias/articulo/ministerio-de-cultura-responde-a-la-polemica-contra-escritorasmujeres/66722>, y <http://www.revistaarcadia.com/cine/articulo/las-mujeres-colombianas-norepresentaran-a-colombia-en-cine-en-francia/66665>. 
los procedimientos de autofiguración y autopromoción autorial?; ¿hasta qué punto, en estas nuevas plataformas de exposición del yo, esas prácticas de exhibición de la intimidad -esas estéticas de la "extimidad", como las llama la antropóloga argentina Paula Sibila (2008)-, van de la mano de un obrar crítico que asume la propia vida y la propia creación como recursos para plasmar su compromiso político-estético, al mismo tiempo que para denunciar o hacer memoria? ${ }^{2}$

El objetivo de este volumen, por tanto, es observar el papel desempeñado por y atribuido a las escritoras, artistas e intelectuales en el campo cultural latino e hispanoamericano contemporáneo, atendiendo a diferentes aspectos propios de los estudios autoriales recientes desarrollados, sobre todo, en el ámbito anglosajón y, en especial, francófono. En este sentido, el dossier da continuidad a los esfuerzos por resituar la autoría en el panorama teórico y crítico en lengua española que, junto a otros/ as investigadores/as, han llevado a cabo anteriormente las participantes en este dossier; ${ }^{3}$ unos esfuerzos enriquecidos y concretados, en esta ocasión, gracias a la perspectiva latinoamericanista y la perspectiva de género. Sin ánimo de exhaustividad pero con la voluntad de reflejar la diversidad geográfica y generacional (desde el Cono Sur a la frontera tijuanense; desde autoras consagradas como Clarice Lispector o Cristina

2 Un primer espacio de encuentro y diálogo en torno a estas interrogantes fue el IX Seminario Corpografías. Autor-representaciones. Procesos y estrategias de ser autora latinoamericana. Textos, cuerpos, massmedia, realizado el 12 y 13 de junio de 2017 en Casa Amèrica Catalunya (Barcelona, España). Dicha actividad, al igual que este dossier, se inscribe en dos proyectos de investigación financiados por el Ministerio de Economía y Competitividad del Gobierno de España: "La autoría en escena. Análisis teórico-metodológico de las representaciones intermediales del cuerpo/corpus autorial" (FFI201564978-P), desarrollado en el seno del Grupo de Investigación Consolidado Cuerpo y Textualidad (2014 SGR 1316), y "Literatura hispanoamericana y literatura mundial: análisis de correspondencia múltiple de las redes transatlánticas actuales" (FFI2016-78058-P). Además, se vincula a los proyectos "Carto(corpo)grafías: narradoras hispanoamericanas del siglo XXI" (Fondecyt-Chile Regular 1180522), de la Comisión Nacional de Investigación Científica y Tecnológica (CONICYT) del Gobierno de Chile; y "Pensar lo real: autoficción y discurso crítico" (FFI2017-89870-P) (Universidad de Alcalá).

3 Entre otras publicaciones, remitimos a los volúmenes Los papeles del autor/a. Marcos teóricos sobre la autoría literaria (Madrid: Arco Libros, 2016) y Qué es una autora. Encrucijadas entre género y autoría (Barcelona: Icaria, 2019), así como a los monográficos "La autoría a debate: textualizaciones del cuerpo-corpus" (Tropelías. Revista de teoría de la literaura y literatura comparada 24 [2015]); "Autoría y género", Mundo nuevo. Revista de estudios latinoamericanos 16 [2015]; o "Des(a)fiando a autoria. Construções do/a autor/a nas literaturas lusófonas" (Interdisciplinar. Revista de estudos em língua e literatura 26 [2016]). Este trabajo se añade al de otros/as muchos/as investigadores/as como Julio Premat, responsable del volumen Héroes sin atributos. Figuras de autor en la literatura argentina (Buenos Aires: Fondo de Cultura Económica, 2009), o Juan Zapata, coordinador de la antología La invención del autor. Nuevas aproximaciones al estudio sociológico y discursivo de la figura autorial (Medellín: Editorial Universidad de Antioquia, 2014) y traductor del estudio reseñado en este dossier Posturas literarias. Puestas en escena modernas del autor, de Jérôme Meizoz (Bogotá: Universidad de los Andes, 2015). 
Peri Rossi a nuevas “celebridades" como Rita Indiana o Mariana Enriquez), esta conjunción de enfoques permite reflexionar sobre las estrategias de decirse autora, de (auto)representación en la escena pública y de (auto)legitimación en un campo intelectual que continúa siendo patriarcal y heteronormativo y que es indisociable de los contextos sociopolíticos e históricos que condicionan o incluso motivan la producción y la recepción cultural.

Esta es una de las cuestiones que permiten enfatizar las propuestas teóricas que, en las últimas décadas y desde campos como la sociología, la sociocrítica, el análisis del discurso o el postestructuralismo, vienen a revisar la noción de autor para contestar -en palabras de uno de sus más destacados representantes, José-Luis Diaz-, tanto su concepción como "sujeto pleno, anterior a la obra, independiente de sus trayectos", como "los prejuicios modernistas que [rehúsan] tomar[lo] en consideración so pretexto de que el texto, en su más alta expresión, debe operar la muerte de su scripteur" (L'écrivain imaginaire 15). ${ }^{4}$ Frente a la autonomía del campo literario y de la creación que presuponen los discursos heredados del siglo XIX, dicha revisión implica dar cuenta de los múltiples modos en los cuales las condiciones de enunciación, los contextos de producción, los medios de circulación y de exhibición y las modalidades de reconocimiento y legitimación contaminan y habilitan ese espacio supuestamente "puro", individual y solitario en el que se fragua la obra literaria y artística (véase, por ejemplo, Maingueneau, Contre Sainte). Del mismo modo, tales perspectivas evidencian también que el habitante de esta habitación propia no adquiere el estatuto de autor sino mediante su inscripción y su puesta en escena tanto en el terreno textual como en el social y mediático, proporcionando múltiples instrumentos para examinar esta figura que ya no es (solo) un sujeto real, un individuo de carne y hueso, sino el producto de sus excursos en tal espacio institucional, ideológico e imaginario.

Podemos establecer un mapa a grandes rasgos de estas propuestas atendiendo al utillaje teórico y analítico que ofrecen tres de las principales firmas con las que dialogan los artículos incluidos en este volumen: Dominique Maingueneau, Jérôme Meizoz y José-Luis Diaz. La noción retórica de ethos, recuperada y revisada desde el análisis del discurso literario francés encabezado por Maingueneau, permite examinar la "identidad enunciativa" que, en cuanto elemento fundamental de las condiciones de enunciación que (re)valida y (re)produce cualquier discurso, se construye en el texto literario, aunque siempre en diálogo con los modelos que determinan "qué es un autor legítimo" y cómo se inviste de "autoridad enunciativa" en un determinado momento sociohistórico (Le discours 118-119). Es decir, siempre en diálogo con los "posicionamientos" respecto a los cuales se ubica el escritor/a en cuanto actor del campo literario y con las "representaciones sociales" y estereotípicas en las cuales se

4 Si no se indica lo contrario en la bibliografía, las traducciones de las citas francesas son nuestras.

$111 \frac{\text { Revista Iberoamericana, Vol. LXXXV, Núm. 268, Julio-Septiembre 2019, }}{11}$ 677-686 
apoya el destinatario/a para identificar y (re)construir el "cuerpo enunciante" que el texto escenifica como el garante de la enunciación (207). ${ }^{5}$

En la medida en que dicha identificación y (re)construcción incorpora elementos extratextuales (lo que Maingueneau [Le discours 204-206] y Amossy denominan ethos prediscursivo, esto es, el que se colige de las informaciones y representaciones previas de las que dispone el lector/a), esta noción puede vincularse con el concepto de postura que -en la encrucijada entre retórica y sociología- elabora Meizoz. Un concepto que permite interrelacionar los actos enunciativos y los actos institucionales y mediáticos a través de los cuales un/a escritor/a construye una "imagen de sí" en aquellas "situaciones en las que la persona encarna", en la arena pública, "la función autor (intervenciones en los medios de comunicación, discursos en los premios literarios, noticias biográficas, cartas dirigidas a la crítica, etc.)” (“¿Qué entendemos?” 189 y 194). De este modo, la postura permite abordar "el vínculo entre las conductas públicas de los escritores [...] y las técnicas enunciativas que movilizan" (Meizoz en Martens 202), "el impacto de la mediatización de los autores en sus prácticas y en su relación con el público" o los modos en los cuales "el cuerpo físico de los escritores participa en la presentación de sí” (La fabrique 8). ${ }^{6}$

Por su parte, la teoría autorial desarrollada por Diaz permite aunar las cuestiones expuestas y explorarlas desde la perspectiva más general de las representaciones del escritor-"Representaciones según todas las declinaciones posibles": "imágenes, figuras, mitos, fantasmas, clichés, tipos, patterns, etc." (en Amossy y Maingueneau s/p)-, constitutivas de su estatuto ya que autorizan y modelan su enunciación y permiten su reconocimiento, pero también de un fuero interno que no sale indemne de las sucesivas puestas en escena que, destinadas a "asignar[le] una identidad para los demás, le asignan a la vez, por efecto especular, una identidad para si"' (L'écrivain imaginaire 24; cursiva del original). Así pues, su propuesta atiende al carácter "fantasmátic[o] de la práctica literaria" (17), considerando las representaciones que la cruzan como "armaduras" o "dispositivos identitarios" (5 y 23) en las que se apoya la construcción de un escritor imaginario. Esto es, la figura idealizada, deseada y soñada que el autor/a proyecta en diversos espacios de autofiguración (47) y que el lector/a (re)construye (75-77) sirviéndose de estos autorretratos pero también de múltiples heterorretratos: desde el rostro que le esbozan "los pintores, los escultores y los fotógrafos" a la vida que "[le novelan] los biógrafos" y que "esquematizan los manuales" (20). ${ }^{7}$

Estas propuestas coinciden, pues, en tres aspectos fundamentales para repensar la autoría literaria y, por extensión, la autoría artística e intelectual. Como avanzábamos,

\footnotetext{
Sobre la cuestión del ethos, véanse también Maingueneau ("El ethos"), Amossy, Bokobza Kahan y Amossy o Dhondt, Horemans, Vanacker y Vandemeulebroucke.

6 Véase también Saint-Amand y Vrydaghs.

Véase también Vandemeulebroucke y Declercq.
}

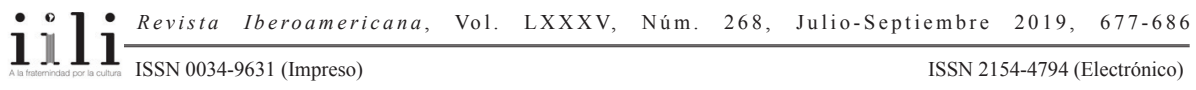


invitan a romper la frontera tradicional entre el interior y el exterior textual; entre el campo literario, representado como autónomo, y los medios y condiciones que se le suponen exteriores y heterogéneos; e incluso entre el fuero interno del creador/a -a menudo concebido como la única y verdadera fuente de la obra-y su inevitable participación en el espacio compartido, discursivo y mediático, de una comunidad no solo literaria sino también social y política. Por otra parte, y como consecuencia, nos muestran que la construcción de una imagen autorial ${ }^{8}$-comprendida como un entramado heterogéneo de representaciones tanto literarias como editoriales, críticas, biográficas, (audio)visuales, digitales, imaginarias, etc.-, es inevitable incluso cuando esta escenifica ese gesto estereotípico del creador/a que es el rechazo de la visibilidad y de la publicidad (véanse Maingueneau Le discours o Heinich 158-167), puesto que, en palabras de Roland Barthes, rehusar la imagen también produce "la imagen de aquel que rehúsa las Imágenes" (en Diaz, L'écrivain imaginaire 23). Un gesto estereotípico que nos viene a recordar, finalmente, que la puesta en escena del autor/a -ya la analicemos en términos de ethos, postura o figura imaginaria-, no depende de elecciones personales, idiosincráticas o singulares sino que tiene lugar en relación con "imágenes codificadas [...] y en cierta medida colectivas" (Diaz, "Paratopies" $\mathrm{s} / \mathrm{p}$ ); como apropiación o reescritura de un "repertorio histórico" de modos de ser, y parecer, escritor/a (Meizoz, “¿Qué entendemos?” 195).

Si nos centramos ahora en las posibilidades que ofrece esta revisión de la autoría desde una perspectiva de género - desatendida, por cierto, por los investigadores mencionados-, podemos advertir dos cuestiones cruciales. En primer lugar, invita a deconstruir la red conceptual que sostiene la noción de autor y que la convierte en un dispositivo de exclusión de género, al mostrar las relaciones constitutivas entre la singularidad (máximo atributo del creador decimonónico y contemporáneo) y la comunidad con la cual las mujeres, vistas como meras reproductoras culturales, hemos sido sistemáticamente confundidas o identificadas; al vincular una instancia autorial tradicionalmente relacionada con el espíritu, el intelecto o la interioridad -en oposición al cuerpo material, animal y femenino- con representaciones visuales o mediáticas necesariamente encarnadas; $;$, en definitiva, al plantear la relación de dicha instancia con la actuación, la performance, la publicidad, el espectáculo, la visibilidad, la apariencia y la dependencia de la mirada ajena, es decir, al relacionar el estatuto de creador con la figura tradicionalmente femenina de la intérprete y de la celebridad mediática (véanse Heinich y Meizoz, "Escribir es entrar").

En segundo lugar, dicha revisión sugiere analizar, por ejemplo, cómo las posturas o los imaginarios autoriales excluyen implícitamente su encarnación en femenino, cómo las creadoras negocian, reescriben o subvierten dicha estereotipia o cómo son

\footnotetext{
Véanse Diaz, Bokobza Kahan y Amossy o Maingueneau ("Escritor e imagen”).
} 
interpretadas, posicionadas e (in)visibilizadas diferentemente sus figuras -y, por ende, su producción- en los espacios de legitimación y de recepción, ofreciendo así nuevas maneras de abordar el concepto de autor, sus representaciones históricas y colectivas y sus encarnaciones individuales como uno de los modos mediante los cuales el arte produce género. En la medida en que su objeto ya no son sujetos reales sino artefactos culturales (véase Cróquer), sugiere hacerlo, además, escapando a la alternativa en la que se vio atrapada parte de la teoría literaria feminista cuando tuvo que enfrentarse a la célebre "muerte del autor": una "muerte" sin duda "prematura" porque contribuía a "invalidar [una] legitimidad [...] lograda apenas frágil y recientemente" (Eagleton 6) e impedía examinar las razones de esta fragilidad; pero una "muerte" cuyo simple rechazo no parecía conducir sino a la problemática interpretación de la producción cultural realizada por mujeres como expresión de un sujeto femenino "anterior a la obra, independiente de sus trayectos" y de las puestas en escena de su ser autora. Son las posibilidades teóricas y críticas que se plantean más allá de esta alternativa las que este dossier propone explorar.

Se abre este volumen con el artículo "Autorías excéntricas. De la crítica cultural latinoamericana y/o transposiciones intelectuales en tiempos de desvanecimiento: Josefina Ludmer/Sylvia Molloy”, de Eleonora Cróquer. En este, su autora - un referente en los estudios autoriales recientes- identifica a las intelectuales argentinas como dos "casos" de pensadoras latinoamericanas excéntricas, descolocadas respecto al latinoamericanismo heterodoxo, que han velado por nuevos formatos de prácticas académicas críticas. Atendiendo al blog de Ludmer y a su libro Aquí América Latina. Una especulación (2010) señala a la autora como una investigadora cuyas lecturas y performances, problemáticas y problematizadoras, la conducen a una autoría propia de una activista-agitadora cultural; mientras que, centrándose particularmente en su obra Desarticulaciones (2010), destaca cómo Molloy desplaza la escritura objetiva hacia una escritura "abiertamente amorosa y en gran medida autobiográfica" y/o autoficcional.

Si bien prácticamente todos los "casos" analizados en este dossier dan cuenta de cómo las respectivas creadoras asumen lo intelectual y lo autorial como político, destacan en esta línea los artículos de María Teresa Vera-Rojas y Tania Pleitez, puesto que en las figuras autoriales abordadas por ambas la escritura y creación de lo individual y personal es también correlato de lo colectivo y nacional, así como un intento por enunciar lo contraoficial. En "Escenas de la memoria/escenas del yo: autorrepresentaciones de un país en las crónicas de Elisa Lerner", Vera-Rojas ofrece una lectura de las crónicas de la escritora venezolana, compiladas en su libro Así que pasen cien años. Crónicas reunidas (2016), y del corto documental Yo, Elisa Lerner (2015), de César Cortez. La autora atiende a cómo Lerner (1932), bajo un consciente proceso de autorrepresentación, se sirve de la crónica - ese género híbrido, marginal y fragmentario-para "registrar escenas de la historia no oficial de Venezuela durante el siglo

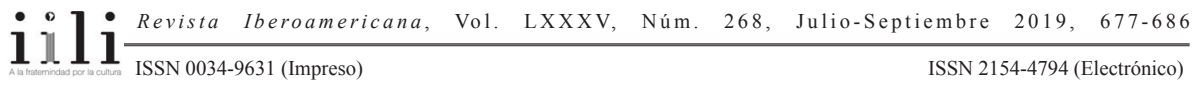


XX", así como para reflexionar en torno a las desigualdades sociales, las experiencias femeninas y el lugar de las escritoras en el campo de las letras venezolanas. Por su parte, en "El cuaderno colectivo de Mayra Barraza: espejo de una obra en singular", Pleitez analiza la bitácora personal de la artista salvadoreña Mayra Barraza (1966), 100 días en la República de la Muerte (2006), y plantea que tanto los post como los retratos de la artista presentados en su exposición "República de la muerte" -que funcionan como autorretratos o autorrepresentaciones pictóricas-, se configuran como "escenarios visuales" que reflejan las violencias políticas, particularmente las dirigidas a las mujeres, incrustadas en el tejido social salvadoreño, es decir, como memoria y testimonio, colectivo e individual, de los dolores de una "nación ultrajada".

Por otro lado, los dos artículos siguientes se centran en el análisis de autorías configuradas mediante la unión de la creación y la propia experiencia de las escritoras. Tal es el caso del estudio que presenta Meri Torras en "Cristina Peri Rossi. Entretejer vida y literatura, ante el despojo del tiempo", donde, a partir del análisis del artículo autobiográfico "Detente un instante, eres tan bello" (2017), plantea cómo en la autora uruguaya (1941) literatura y vida transitan inseparablemente. Así, la escritora se inscribe dentro de los autores/as-creadores/as que "reclaman el derecho de inventarse a sí mismos", de ficcionalizarse y de coquetear con la autoficción, colocándose "en un terreno fronterizo entre invención y facticidad", donde ambos se confunden deliberadamente, y a quienes los críticos implícitos no solo asedian sino que también participan como cómplices implicados de dicha creación autorial. Asimismo, en "Mayra Luna y la escritura como sanación en una autora fronteriza", Elena Ritondale analiza la construcción autorial de la tijuanense Mayra Luna (1974), a partir de su posición "periférica" con respecto al campo literario centralista mexicano, tanto por el lugar geográfico desde donde escribe -transfronterizo-, como por el hecho de desarrollar una escritura híbrida en la que se entreteje investigación, creación y autoconocimiento. Para ello, Ritondale revisa sus diferentes enunciados - desde sus entrevistas y algunos de sus post en su blog personal y en "Tijuana Bloguita Front", hasta los textos literarios incluidos en Lo peor de ambos mundos. Relatos anfibios (2006)-y los pone en relación con su labor como psicoterapeuta y traductora, a fin de dar cuenta de cómo, para la autora, la escritura es una práctica de sanación.

El bloque final del dossier está conformado por cuatro artículos en los que se aborda la construcción de la autoría prestando atención a diferentes paratextos y soportes de autofiguración a los que han acudido las respectivas escritoras. Lorena Amaro, en "La dificultad de llamarse 'autora': Mariana Enriquez o la escritora weird", propone una aproximación a la imagen de la narradora y periodista cultural argentina Mariana Enríquez (1973) que pone en diálogo paratextos como fotografías y entrevistas, su genealogía literaria y su atracción por los géneros minoritarios, como el género fantástico y de terror o géneros no ficcionales o "referenciales" como las crónicas y la biografía

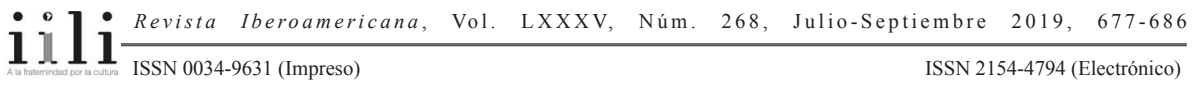


literaria. Es decir, pone énfasis en su relación con estos espacios creativos marginales que la han llevado a ser vista por la crítica como una escritora "rara", ecléctica, que opta por una escritura que puede ser tanto queer como weird.

En "Expresar un posicionamiento, exponer la intimidad: la imagen de autora en Rita Indiana y su 'yo' autorial”, Fernanda Bustamante hace un recorrido por las diferentes facetas que ha configurado la artista dominicana Rita Indiana (1977) y por las escenografías autoriales por las que ha transitado. Para ello, la autora revisa y problematiza sus obras literarias, musicales y performativas, su comportamiento en redes sociales (Facebook y Twitter), sus columnas en Prodavici y El Pais, junto a diversas entrevistas, analizando asimismo su propio nombre y apodo. Todos estos elementos los presenta como piezas fundamentales en la construcción y escenificación de la imagen y postura de autora de Rita Indiana -disidente, disruptiva, contestataria, comprometida, particularmente en lo que se refiere a los colectivos marginados por su condición de raza o género-, problematizando la relación de estos con su reconocimiento literario y con su celebridad como artista musical.

Ahondando en la cuestión de la hipervisibilidad que pueden llegar a poseer las autoras y en la función de la fotografía como dispositivo visual de figuración autorial, en "Wendy Guerra: posar desnuda... ¿en La Habana?" Dunia Gras se plantea la importancia de la imagen fotográfica como modo de visibilización en el actual campo literario transnacional en español, y reflexiona sobre los peligros del desnudo en la recepción literaria de autores/as que lo han practicado como forma promocional. Para ello, analiza el caso de la escritora cubana Wendy Guerra (1970) sirviéndose de los retratos de desnudos que le hizo el fotógrafo argentino Daniel Mordzinski, en el marco del grupo Bogotá 39; de su imagen ilustrando la portada de sus libros; y de las fotografías artísticas de su cuerpo publicadas en la revista $\mathrm{SoHo}$, en Colombia y en México, entre otros soportes.

El último artículo, “'Clarice Lispector'. Extravíos y suplementos de un nombre autorial", de Aina Pérez Fontdevila, problematiza los mecanismos especulares y espectaculares que producen la singularidad y la celebridad autorial a partir del caso de la escritora brasileña Clarice Lispector (1920-1977). Para ello, Pérez Fontdevila presta especial atención a aquellos agentes que han contribuido a la enigmatización de su figura, centrándose en el único registro audiovisual conservado de la autora -la entrevista que concedió en febrero de 1977 a Julio Lerner en el programa Panorama, de la TV Cultura de São Paulo-a fin de examinar sus modalidades de aparición; el vínculo entre su firma y el motivo de la extranjeridad bio y mitográfica; y la deconstrucción del "nombre propio" que sugiere la reflexión de Lispector sobre el apellido "Lispector" en la citada entrevista audiovidual.

Finalmente, y como parte del dossier, Esther Fernández presenta una reseña de la traducción al castellano de Posturas autoriales. Puestas en escena modernas del

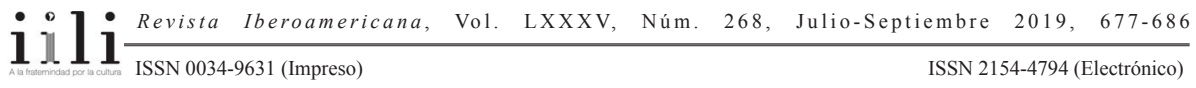


autor (Bogotá: Ed. Universidad de los Andes, 2015), de Jérôme Meizoz, realizada por Juan Zapata. Si bien el volumen no se centra específicamente en las autorías femeninas latinoamericanas, consideramos oportuno incorporarlo en la medida en que es un texto de referencia en los estudios autoriales contemporáneos al cual remiten prácticamente todos los artículos aquí presentados.

\section{BiBLIOGRAFÍA}

Amossy, Ruth. Images de soi dans le discours. La construction de l'ethos. Lausana: Delachaux et Niestlé, 1999.

y Maingueneau, Dominique. "Autour des 'scénographies auctoriales': entretien avec José-Luis Diaz, auteur de L'écrivain imaginaire (2007)”. Argumentation et Analyse du Discours 3 (2009): s/p. <http://journals.openedition.org/aad/656>. 6 dic. 2017.

Bokobza Kahan, Michèle y Amossy, Ruth. "Ethos discursif et image d'auteur", Argumentation et Analyse du Discours, 3 (2009). <http://journals.openedition. org/aad/656>. 6 dic. 2017. [número monográfico].

Cróquer, Elenora. Escrito con rouge. Delmira Agustini (1886-1914): artefacto cultural. Rosario: Beatriz Viterbo, 2009.

Diaz, José-Luis. "Paratopies romantiques". COnTEXTES. Revue de sociologie de la littérature 13 (2013): s/p. <http://journals.openedition.org/contextes/5786>. 6 dic. 2017.

L'écrivain imaginaire: scénographies auctoriales à l'époque romantique. París: Champion, 2007.

Eagleton, Mary. Figuring the Woman Author in Contemporary Fiction. Houndmills/ Nueva York: Palgrave Macmillan, 2005.

Maingueneau, Dominique. "Escritor e imagen de autor". Tropelías. Revista de teoría de la literatura y literatura comparada, 24 (2015): 17-30. <https://papiro.unizar. es/ojs/index.php/tropelias/issue/view/93>. 6 dic. 2017.

"El ethos: un articulador". Los papeles del autor/a. Marcos teóricos sobre la autoría literaria. [2013]. Eds. Aina Pérez Fontdevila y Meri Torras Francès. Madrid: Arco Libros, 2016. 131-154.

Contre Saint Proust, ou la fin de la Littérature. París: Belin, 2006.

Le discours littéraire. Paratopie et scène d'énonciation. París: Armand Colin, 2004.

Martens, David. "La fabrique d'une notion. Entretien avec Jérôme Meizoz au sujet du concept de posture". Interférences littéraires /Literaire interferenties, 6 (2011): 199212. $<\mathrm{http} / /$ interferenceslitteraires.be/sites/drupal.arts.kuleuven.be.interferences/ files/illi6entretienjeromemeizoz.pdf>. 6 dic. 2017.

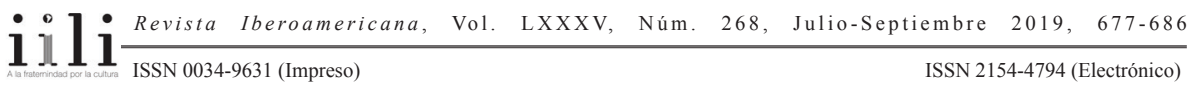


Meizoz, Jérôme. "“Escribir, es entrar en escena': la literatura en persona”. Estudios. Revista de investigaciones literarias y culturales, 42 (2016): 253-269. <http:// www.revistaestudios.ll.usb.ve/node/61>. 6 dic. 2017.

La fabrique des singularités. Postures Littéraires II. Ginebra y París: Slatkin Erudition, 2011.

“¿Qué entendemos por 'postura”?.Los papeles del autor/a. Marcos teóricos sobre la autoría literaria. [2007]. Eds. Aina Pérez Fontdevila y Meri Torras Francès. Madrid: Arco Libros, 2016. 187-294.

Revista Arcadia. "La versión del ministerio de Cultura". Arcadia. 16 nov. 2017. <http:// www.revistaarcadia.com/noticias/articulo/ministerio-de-cultura-responde-a-lapolemica-contra-escritoras-mujeres/66722>. 6 dic. 2017.

Saint-Amand, Denis y Vrydaghs, David. "Retours sur la posture". COnTEXTES. Revue de sociologie de la littérature, 8 (2011). $<\mathrm{http} / /$ journals.openedition.org/ contextes/4712>. 6 dic. 2017. [número monográfico].

Sibila, Paula. La intimidad como espectáculo. Buenos Aires: Fondo de Cultura Económica, 2008.

Vandemeulebroucke, Karen y Declercq, Elien. "De l'écrivain au traducteur imaginaires. Entretien avec José-Luis Diaz au sujet de sa théorie de l'auteur". Interférences littéraires/Literaire interferenties, 9 (2012): 211-227. < http://www. interferenceslitteraires.be/node/179>. 6 dic. 2017.

VV.AA. "Las escritoras colombianas hacen público un manifiesto". Arcadia. 8 nov. 2017. $<\mathrm{http}$ ://www.revistaarcadia.com/noticias/articulo/mujeres-escritoras-colombianasprotestan-discriminacion-politica/66572>. 6 dic. 2017.

Zuluaga, Pedro Adrián. "Tampoco en el cine las mujeres representarán a Colombia en Francia". Arcadia. 14 nov. 2017. <http://www.revistaarcadia.com/cine/articulo/lasmujeres-colombianas-no-representaran-a-colombia-en-cine-en-francia/66665>. 6 dic. 2017. 